
ra, Brasília, v.22, n.4, p.734-739, out-dez 2004.

\title{
Efeitos da fertirrigação sobre a produção de palmito da pupunheira
}

\author{
Adriana Ramos ${ }^{1}$; Marilene L.A. Bovi²; Marcos Vinícius Folegatti ${ }^{1}$; Adriano V. Diotto ${ }^{1}$ \\ 'ESALQ, C. Postal 9, 13418-900 Piracicaba-SP; E-mail: aramos23@ bol.com.br; ${ }^{2}$ Instituto Agronômico, C. Postal 28, $13001-970$ \\ Campinas-SP; E-mail: mlabovi@iac.sp.gov.br
}

\section{RESUMO}

Com o objetivo de avaliar o efeito da aplicação de lâminas de irrigação e níveis de adubação nitrogenada na produção de palmito de pupunheira (Bactris gasipaes Kunth), foi conduzido um experimento a campo, durante 22 meses, em Piracicaba (SP). Empregouse o delineamento em blocos casualizados, com tratamentos distribuídos em esquema fatorial 3 (nitrogênio) x 4 (lâminas). Os níveis de nitrogênio corresponderam a $0 ; 200$ e $400 \mathrm{~kg} \mathrm{ha}^{-1} \mathrm{ano}^{-1}$ de $\mathrm{N}$, aplicados por meio de fertirrigações semanais. As lâminas de irrigação foram equivalentes a 0;50; 100 e $120 \%$ da evapotranspiração de referência (Eto), determinada em função de tanque classe A. A produção de palmito por planta foi avaliada dos 30 aos 34 meses após o plantio. Houve efeito significativo dos tratamentos (irrigação e adubação) para todas as variáveis relacionadas à produção. Os tratamentos com menores lâminas e doses de nitrogênio apresentaram as menores produções. Levando-se em conta o crescimento da planta e a produção de palmito, os resultados indicam que irrigação com $100 \%$ da ETo e fertirrigação com $200 \mathrm{~kg} \mathrm{ha}^{-1}$ ano $^{-1}$ de N são as recomendadas para a pupunheira cultivada em condições de solo, clima e manejo cultural semelhantes às deste estudo.

Palavras-chave: Bactris gasipaes, adubação, irrigação, pupunha, nitrogênio, rendimento.

\begin{abstract}
Fertirrigation in peach palm: effects on heart-of-palm yield

Peach palm (Bactris gasipaes Kunth) yield responses were evaluated, using four irrigation levels and three nitrogen doses, in a field experiment carried out, during a 22-month period, in Piracicaba, São Paulo State, Brazil. A randomized block trial in a factorial design was utilized. Nitrogen doses corresponded to $0 ; 200$ and $400 \mathrm{~kg}$ ha ${ }^{1}$ year $^{-1}$ of $\mathrm{N}$, whereas irrigation levels were equivalent to $0 ; 50 ; 100$ and $120 \%$ of the daily reference evapotranspiration (ETo), determined by a class A evaporation pan. Weekly fertirrigations were applied using a diaphragm injection pump. Heart-of-palm yield was evaluated from 30 to 34 months. There were significant treatment (irrigation and fertilization) effects for all yield related variables. The treatments with low irrigation levels and nitrogen doses presented the smallest yields. Taking into consideration plant growth and heart-of-palm yield, the results indicate that irrigation with $100 \%$ of ETo and fertirrigation with $200 \mathrm{~kg}$ of $\mathrm{N} \mathrm{ha}^{-1}$ year-1 are recommended when cultivating peach palm plants in conditions similar to the ones presented in this study.
\end{abstract}

Keywords: Bactris gasipaes, ammendement, irrigation, palmito, production, nitrogen.

\section{(Recebido para publicação em 13 de fevereiro de 2004 e aceito em 2 de setembro de 2004)}

$\mathrm{O}$ palmito é uma iguaria fina, de grande aceitação no mercado brasileiro. Não obstante, o palmito é também muito apreciado em outros países como França, Japão, Itália, Estados Unidos, entre outros, o que torna o Brasil o maior produtor, consumidor e exportador de palmito em conserva. Entretanto, apesar de ser o maior produtor de palmito, o Brasil ainda explora o produto de forma extrativa, baseada quase que totalmente no aproveitamento e degradação das reservas naturais, havendo a necessidade de uma exploração racional em substituição a exploração predatória (Bovi et al., 1988).

A pupunheira (Bactris gasipaes Kunth) surge como uma opção para atender a demanda interna e externa, por apresentar características desejáveis quanto ao seu cultivo e qualidade do palmito produzido. Quando cultivada em condições adequadas, apresenta rápido crescimento, produzindo palmito de boa qualidade e plantas com bom perfilhamento, o que confere caráter permanente de exploração à cultura. Como os primeiros estudos realizados com a palmeira pupunha para produção de palmito no Brasil datam de 1978 (Germek, 1978), ainda são poucas as informações quanto às necessidades hídricas e nutricionais dessa cultura, quando cultivada no estado de São Paulo. Embora a área cultivada com pupunheira do tipo inerme atualmente seja acima de 60.000 ha (Bovi, 2003), os insucessos são freqüientes devido à falta de conhecimento sobre a cultura, como sua exigência em características físicas do solo, principalmente no que se refere à compactação e drenagem, necessidade de adubação elevada para máxima produtividade e sua exigência hídrica, sendo necessária irrigação quando cultivada em áreas com déficit hídrico (Bovi, 1997; Bovi et al., 1997).

Estudos sobre uso e manejo de água são freqüentes em outras palmeiras, especialmente com o coqueiro, tal como reportado por Nelliat (1968), Parthasarathy (1984), Liyanage e Mathes (1989) e Mathew et al. (1993). Os resultados indicaram que a irrigação é fundamental para maior produtividade, alcançando níveis adequados quando do suprimento de $100 \%$ da evaporação do tanque classe A. Em pupunheira os estudos nessa área são mais recentes. Vizquez (1981), na Costa Rica, foi o primeiro a ressaltar a possibilidade de que a irrigação seja economicamente recomendada para o cultivo de pupunheira em regiões com baixos índices pluviométricos. No Brasil, merecem destaque os estudos de Ramos e colaboradores (Ramos, 1998 ; Ramos et $a l, 2001)$ realizados em Piracicaba e os de Bassoi e co-autores (Bassoi et al., 1999; Bassoi et al., 2003) efetuados em Juazeiro (BA). Pesquisas realizadas no mesmo período em Ilha Solteira (SP), em conjunto com resultados obtidos por Ramos (1998) em Piracicaba, permitiram o desenvolvimento de um progra- 
ma computacional que avalia a viabilidade econômica da irrigação nessa cultura (Marques e Marques, 2002; Marques e Coelho, 2003).

O consumo hídrico pela cultura é elevado, conforme apontam os resultados obtidos por Ramos (1998), Diotto (1999) e Bassoi et al. (2003). Valores médios de coeficiente de cultura $(\mathrm{Kc})$ variando de 0,72 a 1,20 para a plantamãe e perfilhos foram encontrados por esses autores, para os períodos que abrangem desde a formação da cultura até a segunda colheita. Ramos et al. (2001) ressaltam ainda que não só a quantidade de água, mas também a freqüência com que ela é aplicada, interferem no crescimento da planta. Para a mesma quantidade de água, um turno de rega a cada dois dias é recomendado. Marques e Coelho (2003) aventam que a irrigação será viável nesse cultivo quando houver um acréscimo de produtividade acima de 130,33\% da obtida em cultura não irrigada.

Não obstante a importância da água, é reconhecida a essencialidade da adubação nitrogenada no crescimento e na produtividade das palmeiras. O nitrogênio é vital para o crescimento vegetativo, uma vez que é largamente utilizado na síntese de proteína e faz parte da estrutura da molécula de clorofila. Na ausência de adubação nitrogenada, a deficiência em nitrogênio é pronunciada, com efeitos significativos sobre o crescimento vegetativo e a produção das palmeiras (Tampubolon et al., 1990; Bonneau et al., 1993; Rodrigues et al. 1997; Secretaria e Maravilla, 1997; Chepote et al., 1998; Bovi et al., 2002a).

Zamorra (1984) foi o primeiro a ressaltar a importância do nitrogênio para a pupunheira. Em ensaio a campo, com diferentes doses de nitrogênio, fósforo e potássio, esse autor verificou que o nitrogênio foi o elemento que mais influenciou a produção de biomassa. Gusman (1985), em experimento realizado na Costa Rica com a pupunheira, avaliou quatro doses de nitrogênio sobre as características: peso médio do palmito bruto e líquido, rendimento bruto e número de palmito por hectare-ano e verificou que o aumento de nitrogênio influenciava positivamente os parâmetros avaliados, até a dose de $367 \mathrm{~kg}$ de $\mathrm{N} \mathrm{ha}^{-1}$ ano ${ }^{-1}$. Respostas semelhantes à adubação nitrogenada foram detectadas recentemente por outros autores (Deenik et al., 2000; Bovi et al., 2002a; Molina et al., 2002). Bovi e colaboradores (Bovi et al.,1999; 2000; 2002a) ressaltam a importância desse elemento influindo não só no acúmulo da biomassa aérea, mas também na biomassa radicular da pupunheira. $\mathrm{O}$ nitrogênio influencia ainda algumas características do palmito, tais como $\mathrm{pH}$ inicial e poder tamponante (Bovi et al., 2002b).

Este trabalho teve como objetivo avaliar o efeito de aplicação de lâminas de irrigação por gotejamento com níveis de adubação nitrogenada sobre a produtividade da cultura da pupunheira, avaliada durante o primeiro ciclo de colheita.

\section{MATERIAL E MÉTODOS}

O estudo foi conduzido na ESALQ/ USP, em Piracicaba (576 $\mathrm{m}$ anm, 22 42’30'S e 47³0'00' W). O solo classificado como Terra Roxa Estruturada (Alfisol), série Luiz de Queiroz, apresenta $5 \%$ de declividade média. $\mathrm{O}$ clima é do tipo CWA, subtropical úmido, com verão chuvoso e inverno seco. A precipitação média anual é $1247 \mathrm{~mm}$, a temperatura média $21,1^{\circ} \mathrm{C}$, a umidade relativa média $74 \%$ e a velocidade do vento $2,2 \mathrm{~m} \mathrm{~s}^{-1}$, com direção predominantemente E/SE (Ometto, 1981).

$\mathrm{O}$ delineamento experimental empregado foi em blocos casualizados, em ensaio fatorial $3 \times 4$, sendo três doses de nitrogênio e quatro lâminas de irrigação, com doze tratamentos e quatro repetições, totalizando quarenta e oito parcelas. Cada parcela foi composta por 32 plantas, sendo 24 plantas de bordadura e oito plantas úteis, centrais.

Os tratamentos referentes às lâminas de irrigação foram: L1 = 0; L2 = 50; L3 = 100 e L4 = 120\% da evaporação medida por um tanque classe A, com modificações desenvolvidas por Amorim Neto (1983), localizado na estação meteorológica que se encontra próxima à área experimental.

Os diferentes níveis de nitrogênio aplicados foram respectivamente: $\mathrm{N} 1=$ 0; N2 = 200; e N3= $400 \mathrm{~kg}$ de $\mathrm{N} \mathrm{ha}^{-1}$ $\mathrm{ano}^{-1}$, com base na recomendação de adubação para a pupunheira apresentada por Bovi e Cantarella (1986).
$\mathrm{Na}$ área experimental foi instalado um plantio de pupunheira, em maio de 1999, no espaçamento de 2,0 x 1,0 m, através de sulcos. No plantio foram aplicados no sulco $20 \mathrm{~kg}$ de esterco de curral curtido e $140 \mathrm{~kg}$ de superfosfato simples por hectare.

Foram instalados tensiômetros na profundidade de $0,15 \mathrm{~m}$ para determinação do momento de irrigação, que foi realizada toda vez que o tensiômetro acusava tensão de $30 \mathrm{kPa}$. Para aplicação de água, foi empregado um sistema de irrigação localizada, tipo gotejamento. Os gotejadores, do tipo autocompensante, foram inseridos na linha lateral, espaçados entre si de $0,40 \mathrm{~m}$, apresentando vazão de 2,7 litros por hora à pressão de serviço de $30 \mathrm{kPa}$. Foram instaladas, em cada parcela, válvulas reguladoras de pressão de $20 \mathrm{lb} \mathrm{pol}^{-2}$.

A lâmina de água aplicada foi calculada pela equação: $\mathrm{L}=$ ECA. $\mathrm{Kp} \cdot \mathrm{Kr}$ em que: L = lâmina de irrigação (mm); $\mathrm{ECA}=$ evaporação do tanque classe $\mathrm{A}$ $\left(\mathrm{mm} \mathrm{dia}{ }^{-1}\right) ; \mathrm{Kp}=$ coeficiente do tanque, para as condições locais de cobertura vegetal, igual a 0,72 (Sentelhas et al., 1999); $\mathrm{Kr}=$ coeficiente de cobertura do solo $(0,6)$, determinado segundo Keller e Karmeli (1974). Kr = Cs/0,85, em que Cs é o índice de cobertura do solo e expressa a fração da superfície do solo realmente coberta pela folhagem das plantas, vista em projeção sobre o plano horizontal. Foi considerado um Cs de 0,5 .

O tempo de irrigação foi calculado pela equação $\mathrm{Ti}=(\mathrm{L} . \mathrm{A}) /($ nq.q) onde: $\mathrm{Ti}$ = tempo de irrigação (h); L = lâmina de irrigação (mm); $\mathrm{A}=$ área de cada palmeira $\left(1 \mathrm{~m}^{2}\right) ; \mathrm{ng}=$ número de gotejadores por planta; $\mathrm{q}$ = vazão dos gotejadores $\left(\mathrm{L} \mathrm{h}^{-1}\right)$.

Durante o primeiro ano (maio/1999 a abril/2000) da cultura no campo, fase de estabelecimento, foram efetuadas adubações com nitrogênio $(0,08 \mathrm{~kg}$ de $\mathrm{N}$ planta $^{-1}$ ano $^{-1}$ ), baseadas nos estudos realizados por Bovi et al. (2002a), e aplicadas quinzenalmente via água de irrigação. Em relação à irrigação, foi utilizada uma lâmina uniforme, igual a $100 \%$ da evapotranspiração de referência.

Assim que se iniciaram os tratamentos (abril/2000), foram aplicados nitrato de potássio, nitrato de cálcio e uréia 

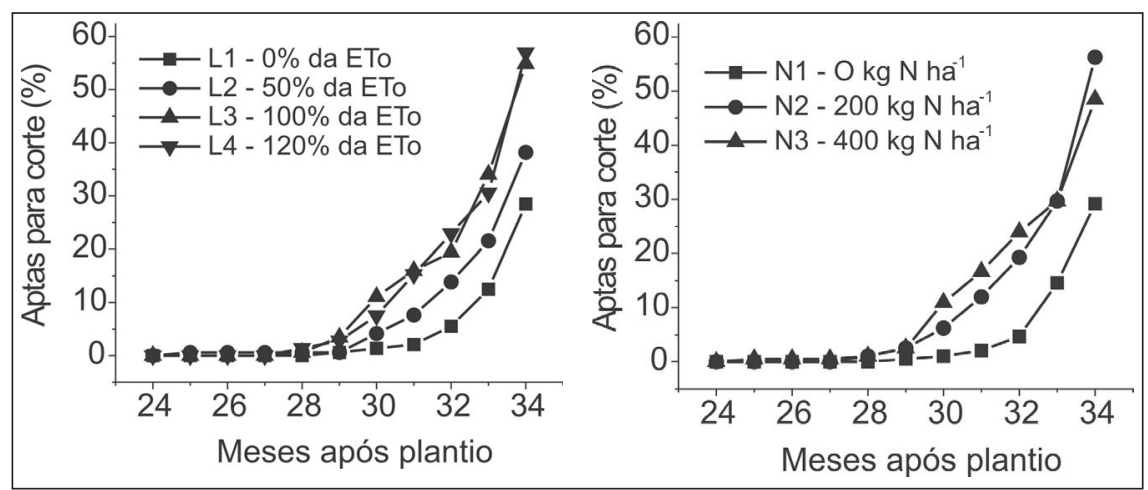

Figura 1. Porcentagem de plantas aptas para corte em função das lâminas de irrigação e doses de nitrogênio. Piracicaba, ESALQ, 2002.

como fonte de nitrogênio. $\mathrm{O}$ nitrato de cálcio foi usado também como fonte de cálcio para suprir os sintomas de deficiência, assim como o nitrato de potássio para suprir a necessidade da cultura desse elemento (200 kg de $\mathrm{K} \mathrm{ha}^{-1} \mathrm{ano}^{-1}$ ). Quando foi utilizado o nitrato de potássio como fonte de $\mathrm{K}_{2} \mathrm{O}$, o restante do nitrogênio necessário foi aplicado na forma de uréia. As fertirrigações foram realizadas pelo emprego de uma bomba TMB; aplicando-se por vez uma lâmina média de água de $3 \mathrm{~mm}$.

A colheita foi realizada entre 30 e 34 meses após o plantio. Para avaliação da produtividade optou-se pela massa fresca de palmito, expressa por planta e por área $\left(\mathrm{t} \mathrm{ha}^{-1}\right)$, separada em palmito de primeira e de segunda, produção total (somatória de palmito de primeira e de segunda) e diâmetro do palmito, segundo recomendação de Clement e Bovi (2000). Foram considerados palmitos de primeira os toletes de $9 \mathrm{~cm}$ de comprimento, completos e sem defeitos físicos ou mecânicos. Para o palmito de segunda, foram contabilizadas as partes referentes ao estipe tenro, também chamado de resíduo basal e a folha tenra, ou resíduo apical.

Os resultados foram submetidos à análise de variância e de regressão, procedimento adequado pela natureza quantitativa dos tratamentos. Os efeitos de regressão foram desdobrados em lineares e quadráticos. A escolha da equação que melhor se ajustou aos dados foi baseada na significância do efeito da regressão, dos desvios da regressão testados pelo teste $\mathrm{F}$ a $5 \%$ de probabilidade e no maior coeficiente de determinação $\left(\mathrm{R}^{2}\right)$. Os coeficientes das equações de regressão foram testados até $10 \%$ pelo teste " $\mathrm{t}$ ". As derivadas primeiras das equações foram igualadas a zero, determinando-se as lâminas de água e as doses de nitrogênio associadas ao valor máximo da varíavel em estudo.

\section{RESULTADOS E DISCUSSÃO}

Segundo Bovi (1997), a colheita no Brasil é iniciada por volta dos 18 aos 36 meses do plantio, dependendo das condições e locais de cultivo. Os resultados expressos na Figura 1 mostram que para as condições estudadas o desenvolvimento das plantas foi lento, bastante inferior ao reportado para regiões climáticas mais favoráveis, tais como Amazônia e Litoral Norte de São Paulo (Villachica, 1996; Bovi, 1998; Bovi et al., 2002a). Nota-se que aos 34 meses após o plantio menos de $60 \%$ das plantas estavam aptas para corte (Figura 1).

Visando avaliar o efeito dos tratamentos sobre a produção de palmito, o corte foi iniciado aos 30 meses após o plantio, quando pelo menos $10 \%$ das plantas dos melhores tratamentos estavam com $1,60 \mathrm{~m}$ de altura e diâmetro na altura de corte variando de $9 \mathrm{~cm}$ a 12 $\mathrm{cm}$. Foi a partir dessa data que a análise estatística mostrou as primeiras diferenças significativas entre os tratamentos, com ausência de interação significativa para todo o período em estudo. Aos 30 meses tiveram início as diferenças entre doses de nitrogênio, com as doses N2 e N3 (200 e $400 \mathrm{~kg}$ de N ha ${ }^{-1} \mathrm{ano}^{-1}$ ) sendo superiores a dose N1 (sem adubação nitrogenada). As diferenças estatísticas entre as lâminas iniciaram-se aos 31 meses, com L4 e L3 sendo estatisti- camente superiores a L1 ao longo de todo o período.

A análise de variância dos dados de colheita, efetuada aos 30; 32; 33 e 34 meses após o plantio, mostrou que houve efeito significativo entre lâminas para todas as variáveis, com exceção do diâmetro médio de palmito, cujo coeficiente de variação foi muito baixo $(\mathrm{CV}$ $=9,95 \%$ ). Para doses de nitrogênio, o efeito foi significativo para todas as variáveis. Já a interação lâmina x nitrogênio não foi significativa para nenhuma delas, indicando que as respostas referentes à irrigação e adubação foram independentes no presente estudo. A análise de regressão mostrou efeitos lineares e quadráticos significativos tanto para lâminas quanto para nitrogênio. A interação lâmina $\mathrm{x}$ nitrogênio não mostrou efeitos lineares significativos para nenhum dos parâmetros avaliados.

Os tratamentos com déficit hídrico e/ ou ausência de fertirrigação nitrogenada acarretaram em menor crescimento da planta e, conseqüentemente, atraso no corte (Figura 1). Nos tratamentos sem fertirrigação a deficiência em nitrogênio foi pronunciada, pois as aplicações de nitrogênio têm efeitos significativos sobre o crescimento vegetativo de palmeiras (Tampubolon et al., 1990; Bonneau et al., 1993; Rodrigues et al., 1997; Bovi et al., 2002a).

A produtividade do palmito de primeira apresentou efeitos lineares e quadráticos significativos para lâminas de irrigação, com valores bem próximos em todos os tratamentos, com médias observadas de 0,846;0,926; $1,077 \mathrm{e}$ 0,967 t ha $^{-1}$ (e estimadas de 0,835; 0,964; 1,011 e $1,006 \mathrm{t} \mathrm{ha}^{-1}$ ) para os tratamentos L1, L2, L3 e L4, respectivamente (Figura 2).

Em relação ao nitrogênio, a regressão foi quadrática, com produtividades observadas de 0,$77 ; 1,07$ e 1,03 t ha ${ }^{-1}$ para os tratamentos N1, N2 e N3, respectivamente. A maior produtividade observada, considerando o palmito de primeira, foi obtida com a dosagem de $200 \mathrm{~kg}$ de $\mathrm{N} \mathrm{ha}^{-1} \mathrm{ano}^{-1}$ (N2). Produtividade máxima teórica de $1,09 \mathrm{t} \mathrm{ha}^{-1}$ foi estimada, pela equação quadrática, para a faixa de 262 a $290 \mathrm{~kg}$ de $\mathrm{N} \mathrm{ha}^{-1} \mathrm{ano}^{-1}$.

A regressão entre as lâminas de irrigação e a produtividade do palmito de 
segunda também foi significativa. Pela Figura 2, nota-se que para níveis crescentes de irrigação, ocorreram aumentos similarmente crescentes na produtividade. A maior produtividade observada foi obtida em L3 (1,64 tha-1), seguida por L4 (1,61 tha-1) e L2 (1,30 $\left.\mathrm{t} \mathrm{ha}^{-1}\right)$. O menor valor ocorreu em L1 $(1,13 \mathrm{t}$ ha $\left.^{-1}\right)$, resultando em uma queda de $31 \%$ na produtividade em relação a L3.

Para o nitrogênio, os efeitos quadráticos foram significativos, com aumentos crescentes na produtividade do palmito de segunda até certa quantidade de nitrogênio aplicada, ou seja, o ponto de máxima produtividade foi estimado para a dosagem de $250 \mathrm{~kg}$ de $\mathrm{N}$ $\mathrm{ha}^{-1} \mathrm{ano}^{-1}$. A maior produtividade observada foi de $1,70 \mathrm{t} \mathrm{ha}^{-1}$ para os tratamentos que receberam N2 (200 kg ha-1 ano $\left.{ }^{-1}\right)$, seguido por N3 $\left(1,45 \mathrm{t} \mathrm{ha}^{-1}\right)$ e N1 $(1,11 \mathrm{t}$ ha $^{-1}$ ), com redução de $14,71 \%$ e $34,71 \%$ no peso do palmito de segunda, quando comparados ao tratamento N2.

Os tratamentos correspondentes às lâminas 3 e 4 (100\% ETo e 120\% ETo) foram os que proporcionaram as maiores produtividades mensuradas, correspondentes a $2,71 \mathrm{t} \mathrm{ha}^{-1}$ e $2,58 \mathrm{t} \mathrm{ha}^{-1} \mathrm{de}$ palmito total, respectivamente (Figura 2). Os níveis de irrigação L1 e L2 foram os que acarretaram em menores produtividades totais $\left(2,23\right.$ e 1,98 $\left.\mathrm{t} \mathrm{ha}^{-1}\right)$, com redução de 27 e $18 \%$ na produção total de palmito em relação aos tratamentos L3 e L4, respectivamente. Alves Júnior et al. (2000) obtiveram uma produtividade inicial de $2,5 \mathrm{t} \mathrm{ha}^{-1}$, para o tratamento que recebeu lâmina equivalente a $100 \%$ ETo, com corte realizado aos 29 meses de campo. Estes valores são superiores à produtividade brasileira, que tem variado de $1,5 \mathrm{t} \mathrm{ha}^{-1}$ ano ${ }^{1}$ a 2,4 t ha ${ }^{-1}$ ano $^{-1}$, em função das variáveis como clima, irrigação, adubação, espaçamento e número de perfilhos mantidos por hectare (Bovi, 1998; Clement e Bovi, 2000).

Em relação ao nitrogênio (Figura 2), da mesma forma que para peso do palmito de segunda, os efeitos da regressão quadrática foram significativos e o maior peso total de palmito foi obtido para o tratamento $\mathrm{N} 2\left(2,77 \mathrm{t} \mathrm{ha}^{-1}\right)$ e o menor para N1 $\left(1,88 \mathrm{t} \mathrm{ha}^{-1}\right)$. O ponto de
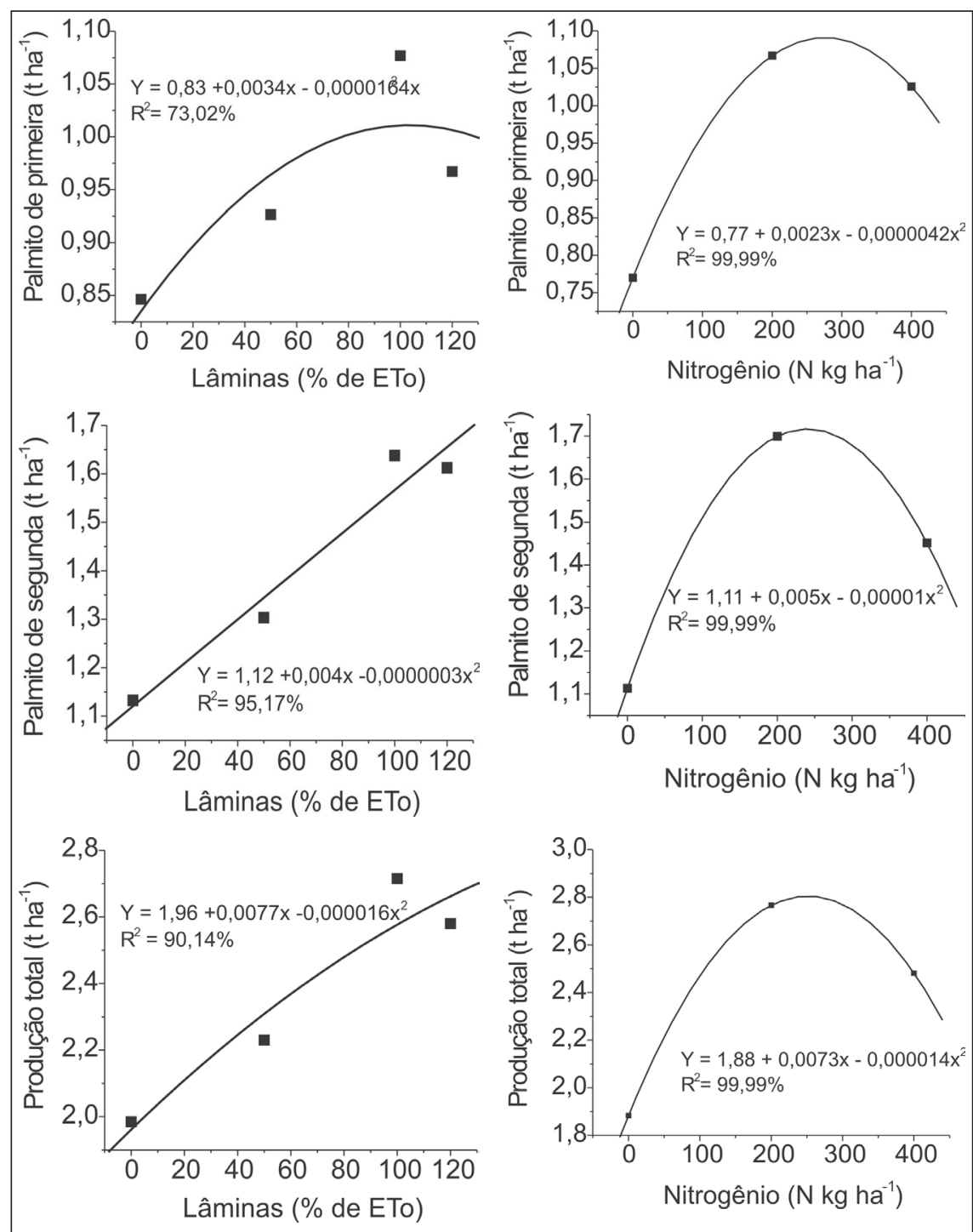

Figura 2. Produção de palmito de primeira, de segunda e produção total em função das lâminas de irrigação e doses de nitrogênio. Piracicaba, ESALQ, 2002.

máxima produtividade foi estimado para a dosagem de $265 \mathrm{~kg}$ de $\mathrm{N} \mathrm{ha}^{-1}$ ano $^{-1}$.

Observa-se pela Figura 2 que as maiores produtividades totais foram obtidas para L3 e L4 e as menores, para os tratamentos com maiores déficits hídricos (L1 e L2) e ausência de fertirrigação nitrogenada (N1). Assim, é possível afirmar que o uso da irrigação foi essencial para que se obtivesse uma produtividade dentro dos padrões já alcançados para o estado de São Paulo. Também, fica evidente a importância da adubação nitrogenada no crescimento e na produtividade da cultura. Essas constatações estão de acordo com Bovi (1998), Deenik et al. (2000), Bovi et al. (2002a e 2002b) e Molina et al.
(2002), que alertam que a produção, além de outros fatores, pode ser muito influenciada pela adubação.

Para diâmetro médio do palmito (Figura 3), a análise de regressão mostrou que não houve efeitos lineares e nem quadráticos significativos, entre as lâminas de irrigação aplicadas. Não obstante a pequena variação de diâmetro (CV 9,95\%) entre e dentro de tratamentos $(2,76 ; 2,79 ; 2,97$ e $2,91 \mathrm{~cm}$, respectivamente para L1, L2, L3 e L4), foi possível ajustar uma equação linear às médias das lâminas de água. Para nitrogênio a regressão mais adequada foi a quadrática, com o diâmetro máximo do palmito $(3,05 \mathrm{~cm})$ sendo estimado para a faixa de 278 a $310 \mathrm{~kg}$ de $\mathrm{N} \mathrm{ha}^{-1} \mathrm{ano}^{-1}$. 


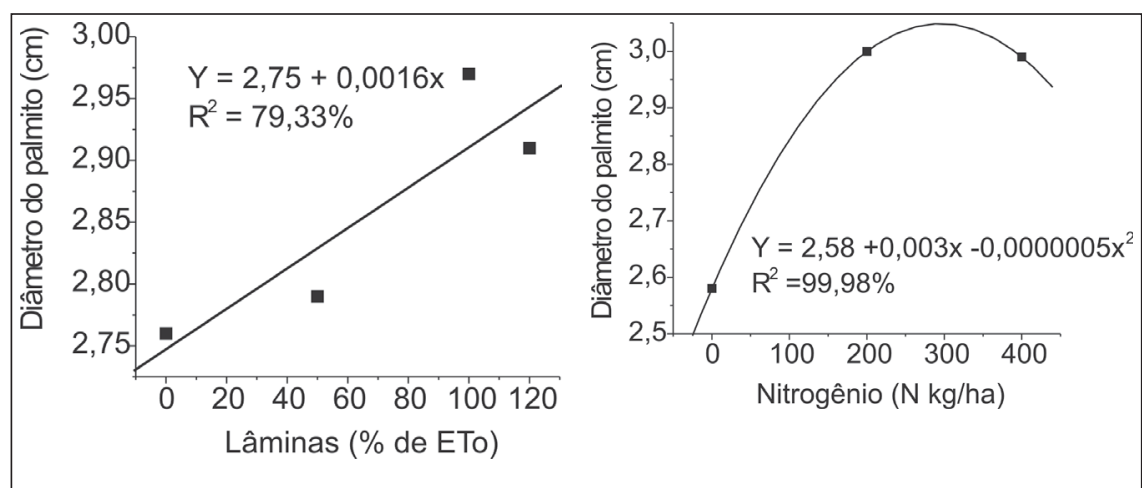

Figura 3. Diâmetro médio do palmito de primeira em função das lâminas de irrigação e doses de nitrogênio. Piracicaba, ESALQ, 2002.

Conclui-se, portanto que os tratamentos L3 (100\% ETo) e L4 (120\% ETo) foram os que proporcionaram uma maior percentagem de plantas aptas para o corte, variando de 40 a $93 \%$, em relação a L1 (testemunha) e L2 (50\% ETo), que apresentaram apenas 8 e $58 \%$ de plantas aptas, respectivamente. As maiores produtividades também foram obtidas em L3 (2,7 $\left.\mathrm{t} \mathrm{ha}^{-1}\right)$ e L4 (2,58 $\left.\mathrm{t} \mathrm{ha}^{-1}\right)$, enquanto que os tratamentos L1 e L2 foram responsáveis por uma redução de 18 a $27 \%$, respectivamente, na produção total de palmito.

Levando-se em conta o crescimento da planta e a ausência de diferenças estatísticas entre os dois melhores tratamentos (tanto para lâminas de água quanto para doses de nitrogênio) quando da avaliação de caracteres relacionados à produção de palmito, os resultados indicam que a irrigação com $100 \%$ da ETo e a fertirrigação com $200 \mathrm{~kg}$ de $\mathrm{N} \mathrm{ha}^{-1} \mathrm{ano}^{-1}$ são as recomendadas para a pupunheira cultivada em condições de solo, clima e manejo cultural semelhantes às do presente estudo. No entanto, os resultados obtidos mostram ser necessário realizar um estudo da viabilidade econômica da irrigação da pupunheira nessas condições, visto que na combinação de tratamentos que proporcionou maior produção de palmito de primeira (L3 e N2) obteve-se um acréscimo de produtividade em relação à testemunha (ausência de irrigação e fertirrigação nitrogenada) de apenas 94,23\%. Esse valor é bastante inferior à 130,33\%, acréscimo de produtividade estimado por Marques e Coelho (2003) como o mínimo necessário para viabilizar a irrigação da pupunheira na região de Ilha Solteira, SP.

\section{LITERATURA CITADA}

ALVES JÚNIOR, J.; HERNANDEZ, F.B.T.; LOPES, A.S.; BERGAMASCHINE, AF. Influência de diferentes níveis de irrigação na cultura da pupunha (Bactris gasipaes H.B.K.) para produção de resíduos, objetivando seu uso na alimentação animal. In: XXIX CONGRESSO BRASILEIRO DE ENGENHARIA AGRÍCOLA, Fortaleza - Ceará, julho de 2000. CD-ROM.

AMORIM NETO, M.S.; VILLA NOVA, N.A. Novo sistema de medidas de evaporação para o tanque classe A. Pesquisa Agropecuária Brasileira, Brasília, v.18, n.7, p.695-702, 1983.

BASSOI, L.H.; FLORI, J.E.; ALENCAR, C.M.; SILVA, J.A.M.; RAMOS, C.M.C. Distribuição espacial do sistema radicular da pupunheira em solos irrigados no Vale do São Francisco. Engenharia Agrícola, v.19, n.2, p.163-176, 1999.

BASSOI, L.H.; FLORI, J.E.; SILVA, E.E.G.; SILVA, J.A.M. Guidelines for irrigation scheduling of peach palm for heart-of-palm production in the São Francisco Valley, Brazil. Horticultura Brasileira, Brasília, v.21, n.4, p.681-685, 2003.

BONNEAU, X.; OCHS, R.; QUSAIRI, L.; LUBIS, L.N. Nutrition minérale dês cocotier hybrides sur tourbe de la pépinière à l'entrée en production. Oléagineux, v.48, p.9-26, 1993.

BOVI, M.L.A. Expansão do cultivo da pupunheira para palmito no Brasil. Horticultura Brasileira, Brasília, v.15 (Supl.), p.183-185, 1997.

BOVI, M.L.A. Palmito pupunha informações básicas para cultivo. Campinas, IAC - Boletim Técnico 173, 1998, 50 p.

BOVI, M.L.A. O agronegócio palmito de pupunha. Horticultura Brasileira, Brasília, v.21, n.1, contracapa, 2003.

BOVI, M.L.A; CANTARELLA, H. Pupunha para extração de palmito. In: RAIJ, B.; CANTARELLA, H.; QUAGGIO, J.A.; FURLANI, A.M.C. Recomendações de adubação para algumas culturas do estado de São Paulo. Campinas: IAC, 1996. p.240-242. (Boletim técnico, 100).

BOVI, M.L.A.; GODOY JR., G.; SAES, L.A. Pesquisas com os gêneros Euterpe e Bactris no Instituto Agronômico de Campinas. In: PALMITO: I ENCONTRO DE PESQUISADORES. Curitiba, PR, 1988. p.1-43.
BOVI, M.L.A.; VIEIRA, S.R.; SPIERING, S.H.; MONTEIRO, S.M.G.; GALLO, P.B. Relações entre crescimento de pupunheira e alguns parâmetros físicos do solo. Trabalho completo, 4 páginas, em CD-ROM. In: XXVI CONGRESSO BRASILEIRO DE CIÊNCIA DO SOLO, Rio de Janeiro, RJ, 20 a 26 de julho de 1997. BOVI, M.LA.; SPIERING, S.H.; BARBOSA, A.M.M. Densidade radicular de progênies de pupunheira em função de adubação de NPK. Horticultura Brasileira, v.17, n.3, p.186-258, 1999.

BOVI, M.L.A.; LAMBAIS, M.R.; TUCCI, M.L.S.; SPIERING, S.H. Biomass accumulation and vesicular-arbuscular mycorrhizal colonization in pejibaye (Bactris gasipaes) as a function of NPK fertilization. Acta Horticulturae, v.513, n.3, p.153168, 2000.

BOVI, M.L.A., GODOY JR., G.; SPIERING, S.H. Resposta de crescimento da pupunheira à adubação NPK. Scientia Agricola, v.59, n.1, p.161-166, 2002a.

BOVI, M.L.A., TUCCI, M.L.S.; SPIERING, S.H.; GOZZI, S.M.G.M.; OLIVEIRA, M.A. J.; GALLO, P.B. Plant mineral fertilization affecting heart-of-palm processing. Acta Horticulturae, 575, v.2, p.643-650, 2002b.

CHEPOTE, R.E.; VALLE, R.R.; SANTANA, C.J.L. Resposta do dendezeiro à adubação mineral. Revista Brasileira de Ciência do Solo, Viçosa, v.12, p.257-262, 1998.

CLEMENT, C.R.; BOVI, M.L.A. Padronização de medidas de crescimento e produção em experimentos com pupunheira para palmito. Acta Amazonica, v.30, n.3, p.349-362, 2000.

DEENIK, J.; ARES, A.; YOST, R.S. Fertilization response and nutrient diagnosis in peach palm (Bactris gasipaes): a review. Nutrient Cycling in Agroecosystems, v.56, n.3, p.195-207, 2000.

DIOTTO, A.V. Balanço hídrico da cultura da pupunheira (Bactris gasipaes Kunth) irrigada por gotejamento. In: $7^{\circ}$ SIMPÓSIO DE INICIAÇÃO CIENTÍFICA DA USP - SICUSP - Agropecuária. 1999. p.366.

GERMEK, E.B. A cultura experimental da pupunha no Estado de São Paulo. In: ANAIS DO IV CONGRESSO BRASILEIRO DE FRUTICULTURA, Cruz das Almas, 1978. Anais... p.409 -411 .

GUSMAN, L.P. Nutrición y fertilización del pejibaye. Informe de Labores de Diversificación Agrícola, ASBANA, n.7, p.41-46, 1985.

KELLER, J.; KARMELI, D. Trickle irrigation design parameters. Transactions of the ASAE, v.17, p.678-684, 1974.

LIYANAJE, L.V.K.; MATHES, D.T. Effect of irrigation on establishment and early growth of coconut (Var. CRIC 60) in the dry zone of Sri Lanka. Cocos, v.7, n.1, p.1-13, 1989.

MARQUES, P.A.A.; COELHO, R.D. Estudo da viabilidade econômica da irrigação da pupunheira (Bactris gasipaes H.B.K.) para Ilha Solteira - SP, Brasil. Ciência Rural, Santa Maria, v.33, n.2, p.291-297, 2003.

MARQUES, P.A.A.; MARQUES, T.A. Programa Pupunha: software para avaliação econômica da irrigação da pupunha. Revista Brasileira de Engenharia Agrícola e Ambiental, v.6, n.2, p.379384, 2002. 
MATHEW, J.; PILLAI, G.R.; SANTHAKUMARI, G; VARGHESE, K. Influence of supplemental irrigation on the productivity and water use of adult coconut palms. Journal of Plantation Crops, v.21, n.2, p.81-87, 1993.

MOLINA, E.; ALVARADO, A.; SMYTH, T.J.; BONICHE, J.; ALPIZAR, D.; OSMOND, D Respuesta del pejibaye para palmito (Bactris gasipaes) al nitrogeno em Andisoles de Costa Rica Agronomia Costarricence, v.26, n.2, p.31-42, 2002. NELLIAT, E.V. Effect of frequency of irrigation on newly planted young coconut palms in sandy soil. Indian Journal of Agricultural Science, v.38, n.4, p.737-746, 1968.

OMETTO, J.C. Bioclimatologia vegetal. São Paulo: Agronômica Ceres, 1981. 440 p.

PARTHASARATHY, M. Drip irrigation of coconuts. Plasticulture, v.64, n.1, p.45-49; 1984. RAMOS, A. Desenvolvimento vegetativo da pupunheira (Bactris gasipaes Kunth) irrigada por gotejamento em função de diferentes níveis de depleção de água no solo. Piracicaba; ESALQ/ USP 66 p (Tese mestrado), 1998.
RAMOS, A.; FOLEGATTI, M.V.; BOVI, M.L.A.; DIOTTO, A.V. Consumo de água da palmeira pupunha (Bactris gasipaes Kunth) pela utilização de lisímetro de drenagem. In: Anais do XI CONIRD e $4^{\mathrm{TH}}$ IRCEW, Ceará-Fortaleza, 2001.

RODRIGUES, M.R.L.; MALAVOLTA, E.; CHAILLARD, H. La fumure du palmier à huile en amazonie centrale brésilienne. Plantations, Recherche, Développement, v.4, p.392-400, 1997. SECRETARIA, M.I.; MARAVILLA, J.N Response of hybrid coconut palms to application of manures and fertilizers from field-planting to full-bearing stage. Plantations, Recherche, Développement, v.4, p.126-138, 1997.

SENTELHAS, P.C.; COELHO FILHO, M.A.; VILLA NOVA, N.A.; PEREIRA, L.R.; FOLEGATTI, M.V. Coeficiente do tanque classe A (Kp) para a estimativa da evapotranspiração de referência. In: CONGRESSO BRASILEIRO DE AGROMETEOROLOGIA, 11 Reunião LatinoAmericana de Agrometeorologia. Programa e resumo dos Anais. Florianópolis: EPAGRI, 1999. p. 223 .
TAMPUBOLON, F.H.; DANIEL, C.; OCHS, R. Résponses du palmier à huile aux fumures azotées et phosphorées à Sumatra. Oléagineux, v.45, p.475-484, 1990.

VILLACHICA, L.M. Cultivo del pijuayo (Bactris gasipaes Kunth) para palmito en la Amazonia. Tratado de Cooperación Amazónica, Lima, 1996. $146 \mathrm{p}$.

VIZQUEZ, N.F.S. Aspectos fenológicos de pejibaye (Bactris gasipaes H.B.K.). Costa Rica: Universidade da Costa Rica. 1981. 60 p. (Tese mestrado).

ZAMORRA, F.C. Densidade de siembra de pejibaye para palmito com tallo dobre. Informe de Labores de Diversificación Agrícola, ASBANA, n.6, p.79-80, 1984. 